ISSN 2466-2232

Online ISSN 2466-2100

\title{
$\mathrm{ENEPIG} / \mathrm{Sn}-\mathrm{Ag}-\mathrm{Cu}$ 솔더 접합부의 취성 파괴에 미치는 무전해 니켈 도금액의 영향
}

\author{
김경호* · 서원일*** · 권상현* · 김준기 ${ }^{*}$ ·윤정원* · 유세훈 ${ }^{*}{ }^{*}$ \\ *한국생산기술연구원 용접접합그룹 \\ **한양대학교 신소재공학과
}

\section{Effects of Ni-P Bath on the Brittle Fracture of Sn-Ag-Cu Solder/ENEPIG Solder Joint}

\author{
Kyoung-Ho Kim*, Wonil Seo*,**, Sang-Hyun Kwon*, Jun-Ki Kim*, Jeong-Won Yoon*, and Sehoon Yoo*, \\ *Joining R\&D Group, Korea Institute of Industrial Technology, Incheon 21999, Korea \\ **Department of Materials Science and Engineering, Hanyang University, Seoul 04763, Korea
}

†Corresponding author : yoos@kitech.re.kr

(Received May 15, 2017 ; Revised May 30, 2017 ; Accepted June 8, 2017)

\begin{abstract}
The effect of metal turnover (MTO) of electroless Ni plating bath on the brittle fracture behavior of electroless nickel electroless palladium immersion gold (ENEPIG)/Sn-3.0wt $\% A g-0.5 \mathrm{wt} \% \mathrm{Cu}(\mathrm{SAC} 305)$ solder joint was evaluated in this study. The MTOs of the electroless Ni for the ENEPIG surface finish were 0 and 3. As the MTO increased, the interfacial IMC thickness increased. The brittle fracture behavior of the ENEPIG/SAC305 solder joint was evaluated with high speed shear (HSS) test. The HSS strength decreased with increasing the MTO of the electroless Ni bath. The brittle fracture increased with increasing the shear speed of the HSS test. The percentage of the brittle fracture for the 3 MTO sample was much higher than that for the 0 MTO sample.
\end{abstract}

Key Words : ENEPIG, Metal turnover, Sn-Ag-Cu, Ni-P, Interfacial intermetallic compound, Brittle fracture

1. 서 론

최근 모바일 기기들의 고사양화에 따라 $\mathrm{I} / \mathrm{O}$ 수가 증 가하면서, 부품의 접합을 위한 솔더의 크기 및 피치가 점점 미세화되고 있다. 모바일 기기들은 사용 중 낙하 충격으로 기기의 고장이 발생되지 않게 하기 위해 높은 신뢰성을 가져야 한다. 하지만, 미세피치 솔더접합부에 서는 접합부의 감소된 크기와 면적으로 인해 낙하충격 특성에 취약하므로, 낙하충격에 대한 신뢰성 확보가 중 요한 문제로 대두된다 ${ }^{1)}$. 낙하충격처럼 빠른 변형률에 의 한 솔더 접합부 신뢰성 저하를 억제하기 위해 $\mathrm{Ni}, \mathrm{In}$, $\mathrm{Pd}$ 같은 미량 원소를 솔더에 첨가하는 방법 ${ }^{2)}, \mathrm{Sn}^{-} \mathrm{Ag}^{-}$ $\mathrm{Cu}$ ( $\mathrm{SAC}$ ) 솔더에서 $\mathrm{Ag}$ 함량을 줄이는 방법 ${ }^{3)}, \mathrm{PCB}$ 표면처리를 변경하거나 특성을 향상시키는 방법 (4) 등의
많은 연구들이 진행되어 왔다. 특히, $\mathrm{PCB}$ 표면처리는 솔더 접합부의 신뢰성에 크게 영향을 주기 때문에 표면 처리와 솔더접합부 간 상관관계를 규명하는 연구들이 많이 진행되어 왔다5,6).

본 연구에서 적용된 표면처리는 Electroless Nickel Electroless Palladium Immersion Gold (ENEPIG) 이다. ENEPIG는 Electroless Nickel Immersion Gold (ENIG)의 문제점인 치환금 도금 시 니켈 부식 을 방지하기 위해 무전해 팔라듐을 무전해 니켈과 치환금 층 사이에 위치 시킨 표면처리이다. 따라서, ENEPIG는 니켈 부식에 의한 블랙패드 불량이 $\mathrm{ENIG}$ 에 비해 아주 적다. 또한, $\mathrm{ENEPIG}$ 는 높은 부식저항특성 및 솔더링 성을 가지며, $\mathrm{Au}$ 및 $\mathrm{Al}$ 와이어본딩과 솔더접합의 표면 처리로 동시에 사용 가능한 넓은 범용성을 가지고 있닥.

본 연구에서는 모바일 제품에서 많이 사용되는 ENEPIG 
표면처리 공정 중, 무전해 니켈 도금 공정에서 도금액 의 상태에 따른 솔더 접합부의 신뢰성에 대해 살펴보고 자 한다. 기존에 발표된 연구 결과에 따르면, 전해 $\mathrm{Cu}$ 도금의 경우 많은 연구들이 도금액에 따라 최종 솔더링 에 영향을 받는다고 보고되고 있다 ${ }^{8-11)}$. $\mathrm{Yu}$ 와 Kim은 전해 $\mathrm{Cu}$ 도금 공정에서 첨가제의 영향에 따라 솔더접 합부의 $\mathrm{Cu} / \mathrm{Cu}_{3} \mathrm{Sn}$ 계면에 발생하는 micro-void의 수 와 크기에 영향을 준다고 보고하였다 ${ }^{11)}$. Yin et al.도 솔더접합부의 micro-void의 형성에 전해 $\mathrm{Cu}$ 도금 공 정조건이 영향을 준다고 보고하고 있다 ${ }^{9)}$. 위와 같이, 솔더 접합 시 솔더와 반응하는 $\mathrm{PCB}$ 표면처리 공정에 서 사용된 도금액과 도금 공정조건이 후속 공정인 솔더 링 시 접합 계면의 미세조직에 크게 영향을 미치는 것 을 알 수 있다. ENEPIG의 경우 일반적으로 치환금과 무전해 팔라듐의 두께가 매우 얇아 솔더링 공정에서 이 들 두 층이 용융솔더에 용해되며, 그 후 남아있는 무전 해 니켈층이 용융솔더와 반응하여 계면 IMC를 형성하 게 된다. 따라서, 취성파괴에 관련이 있는 계면 $\mathrm{IMC}$ 의 형성에 무전해 니켈이 참여하므로, 무전해 니켈의 도금 조건에 따라서 솔더접합부의 취성파괴에 영향이 있을 것으로 판단된다.

Metal turnover (MTO)란 무전해 도금액의 도금 조건을 파악하는 지표 중 하나이다. 무전해 도금을 진 행할수록 도금액에서 금속 이온이 소모되므로, 주기적 으로 금속이온을 보충해주어야 한다. 이 때, 최초 도금 액 내의 금속 이온의 양과 동일한 금속이온을 보충하게 될 때 그 도금액은 $1 \mathrm{MTO}$ 라고 한다. 도금을 계속 진 행하면서 금속이온을 계속 보충해주면 $\mathrm{MTO}$ 가 증가하 게 되며, 도금액의 종류에 따라 다르지만, 일반적으로 $3.0 \sim 3.5 \mathrm{MTO}$ 정도가 되면 도금액은 폐액 상태가 된다. MTO 자체는 금속이온을 얼마나 보충해 주었는 가에 대한 지표이지만, 여기에는 신액과 폐액의 의미도 포함되어 있다. 즉, $\mathrm{MTO}$ 가 크면 도금이 많이 진행된 상태이므로, 도금액은 인쇄회로기판 $(\mathrm{PCB})$ 에서 나온 유 기불순물들이 많이 포함된다. 따라서, 금속이온을 추가 하지 않은 상태는 $0 \mathrm{MTO}$ 로 신액 상태를 나타내며, 도 금이 많이 진행되면 폐액상태가 되는데, 무전해 니켈 도 금액에서는 $3 \mathrm{MTO}$ 정도를 폐액상태로 판단하고 있다.

본 연구에서는 ENEPIG 표면처리 층을 형성할 때, 첫 번째 도금공정인 무전해 니켈 공정에서 도금액을 0 과 $3 \mathrm{MTO}$ 로 변화하여 니켈도금을 진행하였고, 그 후 동일한 조건으로 무전해 팔라듐, 치환금 도금을 진행하 였다. 형성된 ENEPIG 표면처리에 $\mathrm{Sn}-3.0 \mathrm{wt} \% \mathrm{Ag}^{-}$ $0.5 \mathrm{wt} \% \mathrm{Cu}$ (SAC305) 솔더볼을 마운팅하고 리플로우 하였다. 그 후 솔더 접합부의 계면을 관찰하고, 취성파 괴를 분석하였다.

\section{2. 실험 방법}

\subsection{PCB 표면처리}

본 연구에서는 $\mathrm{Cu}$ 패드가 형성된 $\mathrm{FR}-4 \mathrm{PCB}$ 를 기판 으로 사용하였다. $\mathrm{Cu}$ 패드 직경은 $400 \mu \mathrm{m}$ 이었고, 두께 는 $10 \mu \mathrm{m}$ 로 형성되었다. $\mathrm{PCB}$ 의 PSR (Photoimageable solder resist) 두께는 $15 \mu \mathrm{m}$ 이었다. ENEPIG 표면처 리는 $\mathrm{PCB}$ 기판의 $\mathrm{Cu}$ 패드 위에 실시하였다. $\mathrm{PCB}$ 표면 처리 전처리는 산탈지, 소프트 에칭, 촉매공정으로 구 성되었다. 기판상의 오염물 탈지 및 젖음성을 부여하기 위하여 산탈지 세척을 실시하고, 산세를 실시하여 표면 활성화를 진행하였다. 표면활성화 공정 후에 표면 산화 층을 제거하고, 표면 조도를 높여 밀착성을 향상시키기 위해 소프트 에칭을 진행하였다. 무전해 니켈 증착을 위해서는 촉매를 소프트에칭을 실시한 $\mathrm{Cu}$ 패드 표면에 형성하였다. 그 후, 무전해 니켈 도금, 무전해 팔라듐 도금, 치환금 도금을 실시하여 니켈 도금층과 금 도금 층을 형성 시켰다.

무전해 니켈 도금은 도금조 온도 $83^{\circ} \mathrm{C}$ 에서 25 분 실 시하였다. 무전해 니켈 도금액은 0 과 $3 \mathrm{MTO}$ 로 변화 하였다. $0 \mathrm{MTO}$ 는 건욕 상태의 도금액이며 $3 \mathrm{MTO}$ 는 폐액 수준의 도금액이다. 무전해 팔라듐 도금은 $72^{\circ} \mathrm{C}$ 에 서 진행하였다. 치환 금 도금은 온도 $80^{\circ} \mathrm{C}$ 에서 실시하 였다. 도금된 무전해 니켈, 무전해 팔라듐, 치환금의 두 께는 각각 $5 \mu \mathrm{m}, 0.05 \mu \mathrm{m}, 0.05 \mu \mathrm{m}$ 이었다. 각 도금층의 모 식도를 Fig. 1에 나타내었고, 도금 후 ENEPIG의 표면 과 단면은 Fig. 2에 나타내었다.

\section{2 솔더링 공정}

솔더링 공정에 사용된 솔더볼은 $450 \mu \mathrm{m}$ 크기의 SAC305 (ET16E02P, Ducsan Hi-Metal)이었다. 먼저, ENEPIG 표면처리된 $\mathrm{Cu}$ 패드 위에 $\mathrm{SAC} 305$ 솔더페이스트(M705$\mathrm{SHF}, \mathrm{Senju}$ 를 인쇄하였다. SAC305 솔더페이스트의 인쇄조건은 인쇄속도 $20 \mathrm{~mm} / \mathrm{sec}$, 인쇄압력 $2 \mathrm{kgf} / \mathrm{cm}^{2}$, 인쇄 각도 $45^{\circ}$, 스크린 Gap $-0.2 \mathrm{~mm}$, 기판분리 속도 $0.2 \mathrm{~mm} / \mathrm{sec}$ 이었다. 인쇄된 솔더페이스트 위에 볼 마운팅용 메탈마 스크를 사용하여 솔더볼 마운팅을 실시하였다. 볼 마운팅

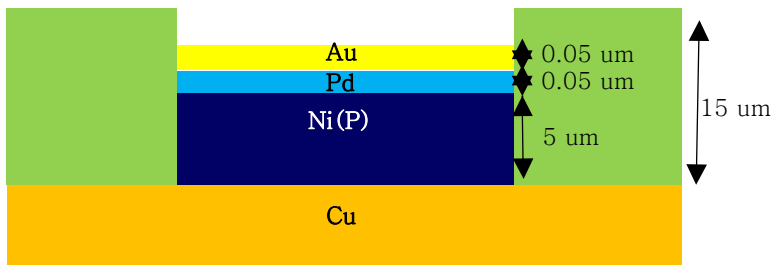

Fig. 1 Schematic illustration of ENEPIG surface finish on $\mathrm{Cu}$ pad of the FR-4 PCB 


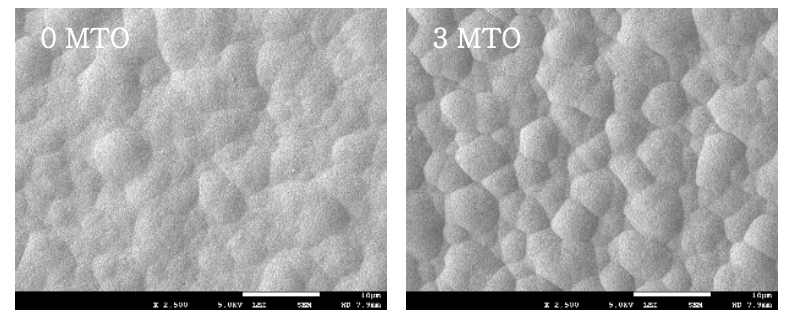

(a) Surface observation of ENEPIG

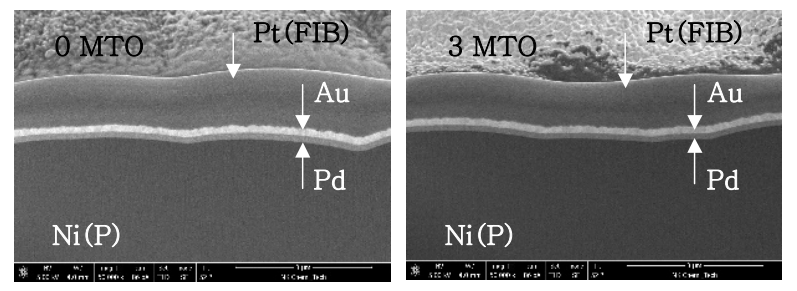

(b) Cross-sectional observation of ENEPIG

Fig. 2 Surface and cross-sectional SEM micrographs after ENEPIG surface finish

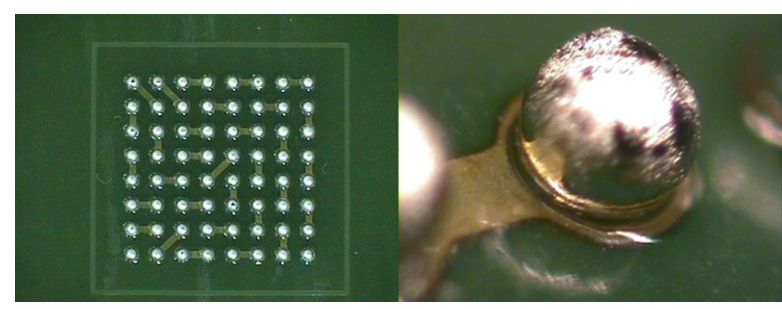

Fig. 3 SAC305 solder ball on ENEPIG surface finish

용 메탈마스크의 홀 직경은 $550 \mu \mathrm{m}$ 이었다. 솔더볼 마운팅 후 솔더볼을 접합하기 위해 리플로우 오븐(1809UL, Heller)을 이용하여 피크 온도 $250^{\circ} \mathrm{C}$ 에서 50 초 간 솔 더링을 실시하였다. 리플로우 공정 후 $\mathrm{ENEPIG}$ 표면처 리에 형성된 SAC305솔더볼 샘플의 이미지를 Fig. 3 에 나타내었다.

\section{3 물성 및 신뢰성 평가}

고온 시효에 따른 계면 금속간 화합물 (IMC)의 변화 를 관찰하기 위해 $150^{\circ} \mathrm{C}$ 에서 500시간 동안 고온 시 효를 실시하였다. 그 후 단면연마를 수행하고, 주사전자 현미경 (SEM, Inspect $\mathrm{F}, \mathrm{FEI}$ ) 으로 솔더 접합부의 계면을 관찰 하였다.

높은 변형률의 고장모드에서 솔더 접합부의신뢰성을 파악하기 위해 고속전단시험을 통해 취성파괴율을 평가 하였다. 고속전단시험은 고속전단시험기 $(4000 \mathrm{HS}$, Dage $)$ 를 이용하였고, 시험은 JEDEC JESD22-B117A 규 격에 의거하여 수행하였다 ${ }^{12)}$. JEDEC 규격에서는 100 $800 \mu \mathrm{m} / \mathrm{s}$ 의 속도로 전단시험을 시행하는 것을 저속전단 시험, 그 이상을 고속전단시험으로 분류하고 있다 ${ }^{12)}$.
또한, 전단높이의 경우 전체 솔더볼 높이의 $25 \%$ 미만을 권장하고 있어, 전단 툴의 높이는 PSR 표면으로부터 $50 \mu \mathrm{m}$ 를 유지하였다. 고속전단시험은 각 조건 별로 25회씩 시험을 진행하였다. 이 때, 전단 속도는 $0.1-2.0 \mathrm{~m} / \mathrm{s}$ 의 조건으로 진행하여, 전단속도의 변화에 따른 전단 강도 및 취성파괴 영향을 확인하였다.

고속전단시험 후 파단면을 $\mathrm{SEM}$ 을 이용하여 확인하 였다. Fig. 4에서와 같이 딤플(dimple)이 있는 연성파 괴 영역과 매끈한 취성파괴 영역을 확인 할 수 있다. 이러한 두 영역의 성분을 확인하기 위하여 $\mathrm{EDS}$ 분석 을 하였다. Fig. 5에서 확인할 수 있듯이 연성파괴 영 역은 $\mathrm{Sn}$ 이 주를 이루므로, 솔더 내부에서 파단이 발생 하였고, 취성파괴 영역은 $\mathrm{Ni}, \mathrm{P}, \mathrm{Sn}$ 이 측정 되는 것을 보아 솔더접합부 계면인 $\mathrm{Ni}-\mathrm{Sn}-\mathrm{P}$ 층 또는 $\mathrm{Ni}_{3} \mathrm{P}$ 층에서 파단이 이루어짐을 확인하였다. 일반적인 접합부 파단 모드는 크게 연성파괴, 연성-취성 복합 파괴, 취성파괴 의 세 가지 모드로 구분하고 있다 ${ }^{13-15)}$. 본 연구에서도 총 25 개의 고속전단시험을 거친 샘플의 파단면을 $\mathrm{SEM}$ 으로 관찰하였고, 연성, 연성-취성 복합, 취성파괴모드 의 세 종류로 구분하였다.
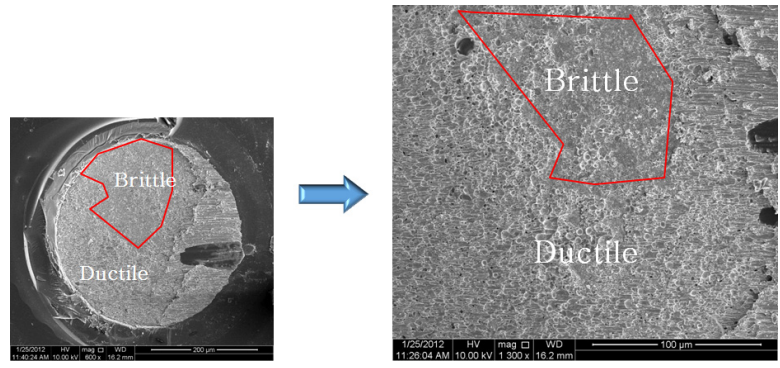

Fig. 4 Ductile and brittle region on the fracture surface after high speed shear test

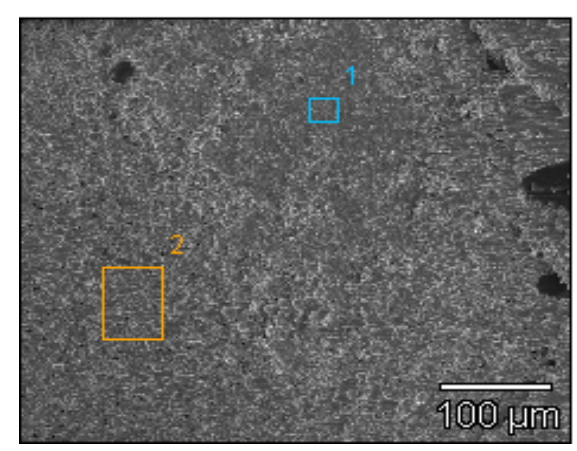

\begin{tabular}{|c|c|c|c|}
\hline & $\begin{array}{c}\text { P-K } \\
(\mathrm{at} \%)\end{array}$ & $\begin{array}{c}\text { Ni-L } \\
(\mathrm{at} \%)\end{array}$ & $\begin{array}{c}\text { Sn-L } \\
(\mathrm{at} \%)\end{array}$ \\
\hline Region 1 & 19.58 & 49.63 & 30.79 \\
\hline Region 2 & & & 100.00 \\
\hline
\end{tabular}

Fig. 5 EDS result of the fracture surface after high speed shear test 


\section{3. 결과 및 고찰}

\subsection{MTO에 따른 솔더접합부 미세조직 변화}

무전해니켈 도금 시 도금액을 0 과 $3 \mathrm{MTO}$ 로 변화하여 ENEPIG 표면처리를 실시한 후, 표면처리 위에 SAC305 솔더볼을 마운팅 및 리플로우 한 후, 접합부를 SEM으 로 관찰하였고, 그 이미지를 Fig. 6에 나타내었다. 리플 로우 후 $\mathrm{ENEPIG}$ 와 $\mathrm{SAC} 305$ 솔더 계면에서는 $\left(\mathrm{Cu}, \mathrm{Ni}_{6} \mathrm{Sn}_{5}\right.$ $\mathrm{IMC}$ 가 형성되는 것을 관찰하였다. $\mathrm{SAC}$ 솔더에서는 솔 더 내 $\mathrm{Cu}$ 의 농도가 낮을 경우에는 $(\mathrm{Ni}, \mathrm{Cu})_{3} \mathrm{Sn}_{4}$, 높을 경우에는 $(\mathrm{Cu}, \mathrm{Ni})_{6} \mathrm{Sn}_{5} \mathrm{IMC}$ 가 형성되며, $\mathrm{Cu}$ 농도가 $0.5 \mathrm{wt} \%$ 인 $\mathrm{SAC} 305$ 솔더의 경우 $(\mathrm{Cu}, \mathrm{Ni})_{6} \mathrm{Sn}_{5} \mathrm{IMC}$ 가 형성된다고 보고되고 있다 ${ }^{16)}$. ENEPIG/SAC305 솔더 접합부의 계면 $\mathrm{IMC}$ 두께는 $\mathrm{MTO}$ 가 증가함에 따라 약 간 증가하였다. IMC 두께는 $0 \mathrm{MTO}$ 샘플에서는 $1.07 \mu \mathrm{m}$ 이었고, $3 \mathrm{MTO}$ 샘플에서는 $1.22 \mu \mathrm{m}$ 이었다. Seo et al. 은 ENIG/SAC305 솔더 접합부에서 $\mathrm{Ni}$ 도금액의 $\mathrm{MTO}$

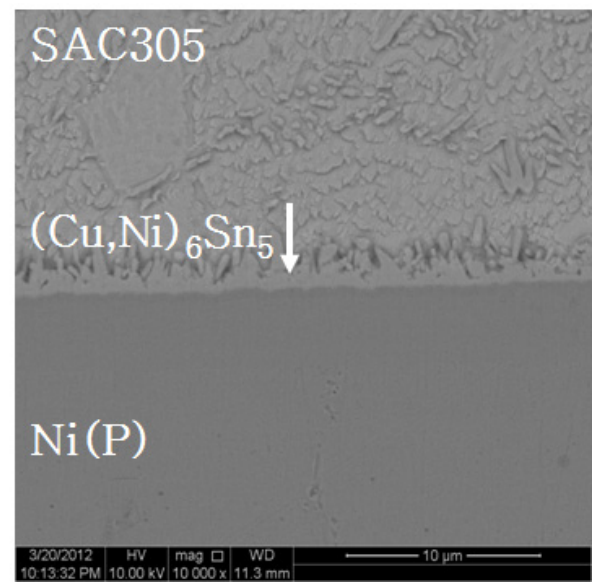

(a)

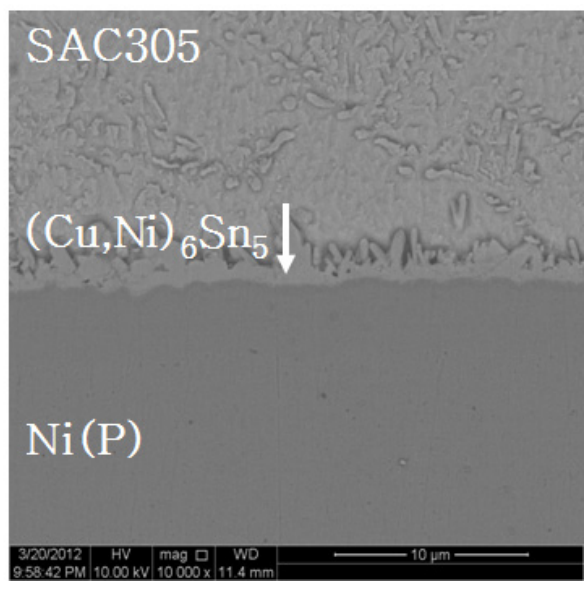

(b)

Fig. 6 Cross-sectional SEM micrographs of the SAC305 solder joint on ENEPIG surface finish. The Ni bath was (a) 0 MTO and (b) 3 MTO

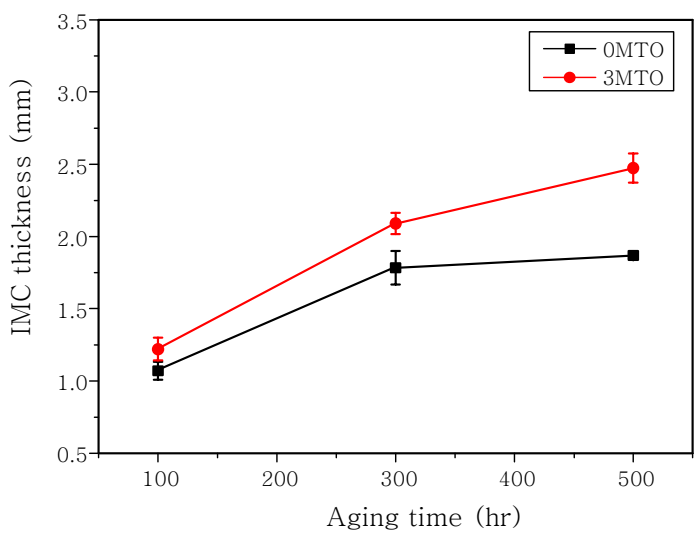

Fig. 7 Interfacial IMC thickness of ENEPIG/SAC305 solder joint vs. thermal aging time with varying MTO of Ni-P plating solution.

를 0 에서 3 으로 변화하면서 $\mathrm{IMC}$ 두께를 관찰하였는 데, $\mathrm{IMC}$ 두께는 $1.43 \mu \mathrm{m}$ 에서 $2.71 \mu \mathrm{m}$ 로 $1.3 \mu \mathrm{m}$ 이상 증가 하였다고 보고하고 있다). 본 연구의 ENEPIG 표면처리 는 $\mathrm{ENIG}$ 만큼 $\mathrm{IMC}$ 두께 증가가 크지 않았다. ENEPIG 표면처리의 경우 무전해 팔라듐 층이 $\mathrm{Ni}$ 과 $\mathrm{Sn}$ 그리고 $\mathrm{Cu}$ 의 확산을 억제하여 ENIG 표면처리에 비해 얇은 $\mathrm{IMC}$ 층을 형성하게 된다 ${ }^{17)}$. 따라서, $\mathrm{MTO}$ 에 의한 $\mathrm{IMC}$ 두께 증가의 효과가 ENEPIG에서는 미미하게 작용하 는 것으로 판단된다.

$150^{\circ} \mathrm{C}$ 에서 500 시간 동안 고온시효 처리 중 계면 $\mathrm{IMC}$ 의 두께를 관찰하였고, 그 결과를 Fig. 7에 나타내었 다. 계면 $\mathrm{IMC}$ 두께는 시효 시간이 증가함에 따라 증가 하였다. 500시간 시효처리 후 $0 \mathrm{MTO}$ 샘플은 $3 \mathrm{MTO}$ 샘플보다 낮은 IMC 두께를 보였다. 따라서, 계면 IMC 두께는 무전해 $\mathrm{Ni}$ 도금액의 상태에 영향을 받음을 알 수 있다. $\mathrm{MTO}$ 의 증가는 $\mathrm{Ni}$ 도금액의 유기불순물의 농 도를 증가시킨다. 전해 $\mathrm{Cu}$ 도금의 경우, 불순물의 첨가 가 microvoid의 불균일 핵생성을 증가시킨다고 보고하 고 있다 ${ }^{9)}$. 본 연구의 무전해 $\mathrm{Ni}$ 층에서도 불순물이 원 자의 빈자리(vacancy)의 발생을 증가시키고, 이를 통해 치환형 확산을 증가시키므로, 불순물이 많은 $3 \mathrm{MTO}$ 샘 플이 $0 \mathrm{MTO}$ 샘플보다 $\mathrm{IMC}$ 의 두께가 두꺼운 것으로 판단된다.

\section{2 솔더 접합부의 취성파괴율}

$\mathrm{MTO}$ 변화에 따른 ENEPIG/SAC305 솔더 접합부 의 취성파괴거동을 파악하기 위해 고속전단강도를 측정 하였고, Fig. 8에 나타내었다. 고속 전단강도는 전단속 도가 증가함에 따라 $0 \mathrm{MTO}$ 와 $3 \mathrm{MTO}$ 샘플 모두 감 소하였다. 일반적으로 전단 속도가 증가함에 따라 솔더 의 전단강도가 증가하다가 일정 전단 속도 이상에서 갑 


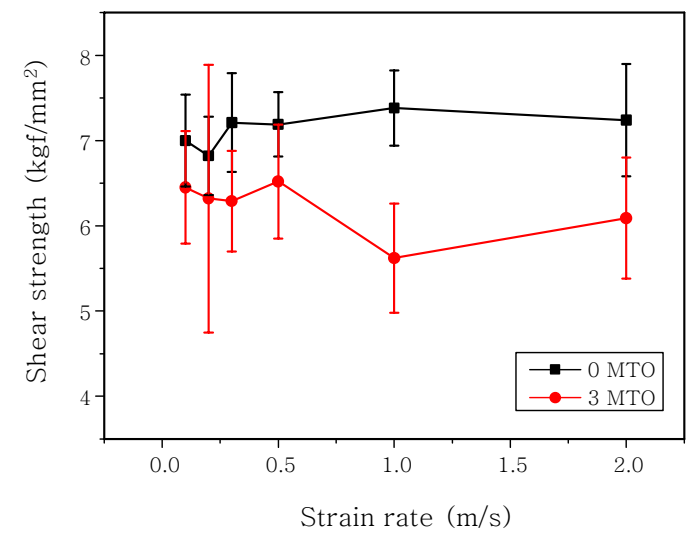

Fig. 8 High speed shear strength of the SAC305 solder on ENEPIG with MTO of Ni-P plating solution

자기 감소하는 모습을 보여주는데, 이것은 전단강도가 증가함에 따라 솔더에서 파괴가 일어나는 연성파괴에서 $\mathrm{IMC}$ 에서 파괴가 일어나는 취성파괴로 모드가 변화하기 때문이다 ${ }^{18)}$. 특히, 취성파괴율이 높은 ENIG 표면처리 에서는 이러한 경향이 두드러지게 된다 ${ }^{4)}$. 본 연구에서 ENEPIG $0 \mathrm{MTO}$ 샘플의 경우에는 전단속도가 증가함 에 따라 전단강도의 급격한 감소가 보이지 않았다. 반면 $3 \mathrm{MTO}$ 샘플에서는 전단속도가 $1.0 \mathrm{~m} / \mathrm{s}$ 이상에서 강도 값의 하락을 보였다. 이러한 전단강도의 하락은 계면 IMC 에서의 취성파괴가 솔더내부에서의 연성파괴보다 더 많 이 발생하는 것이다.

취성파괴 모드를 관찰하기 위해 고속전단시험 후 파 단면을 관찰하였고 Fig. 9에 파괴모드를 나타내었다. 총 샘플 수는 25 개였고, 25 개 샘플 중 연성, 연성+취성, 취성파괴의 세 가지 모드로 나누어 그래프에 표시하였 다. 전단속도가 낮을 경우에는 연성파괴가 대부분을 차 지하지만, 전단속도가 증가함에 따라 취성파괴가 증가 하였다. $0 \mathrm{MTO}$ 샘플의 경우, 전단 속도가 $1 \mathrm{~m} / \mathrm{s}$ 이 상에서 $\mathrm{IMC}$ 에서 $100 \%$ 파괴되는 취성파괴가 관찰되었 다. $3 \mathrm{MTO}$ 샘플의 경우, 가장 낮은 전단속도인 $0.1 \mathrm{~m} / \mathrm{s}$ 에서부터 취성파괴가 관찰되었다. 또한, $1 \mathrm{~m} / \mathrm{s}$ 이상에 서는 취성파괴가 $30 \%$ 이상으로 크게 증가되었다. 따라 서, $3 \mathrm{MTO}$ 샘플이 $0 \mathrm{MTO}$ 샘플보다 취성파괴율이 높고, 전단 강도 값은 낮은 것으로 나타났다.

무전해 $\mathrm{Ni}$ 도금액의 $\mathrm{MTO}$ 가 증가하면서 솔더접합부 의 취성파괴가 증가하는 이유는 $\mathrm{MTO}$ 증가에 따른 $\mathrm{Ni}^{-}$ $\mathrm{Sn}-\mathrm{P}$ 층에서 형성되는 nano-void의 증가로 판단된다. 계면 $\mathrm{IMC}$ 도 취성파괴에 영향을 주지만, 리플로우 후 $0 \mathrm{MTO}$ 와 $3 \mathrm{MTO}$ 샘플간 IMC 두께 차이는 크지 않았으므로, $\mathrm{MTO}$ 변화에 따른 취성파괴율 증가에서는 $\mathrm{IMC}$ 두께 영향은 없는 것으로 판단된다. $\mathrm{ENIG}$ 표면처리의 경우 $\mathrm{MTO}$ 의 증가에 따라 $\mathrm{Ni}-\mathrm{Sn}-\mathrm{P}$ 층에서 형성되는 $\mathrm{nano}^{-}$

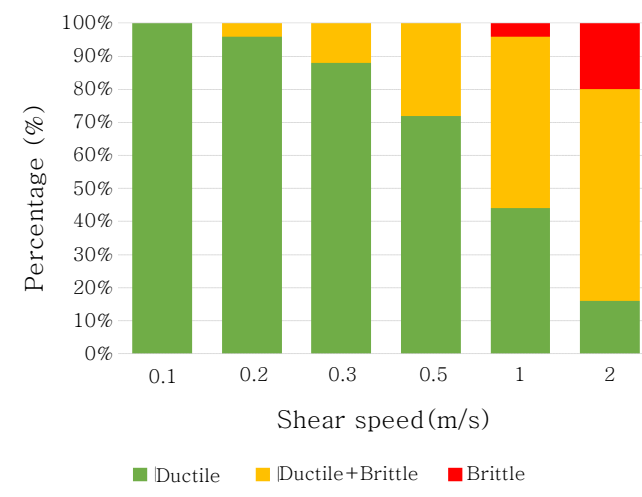

(a)

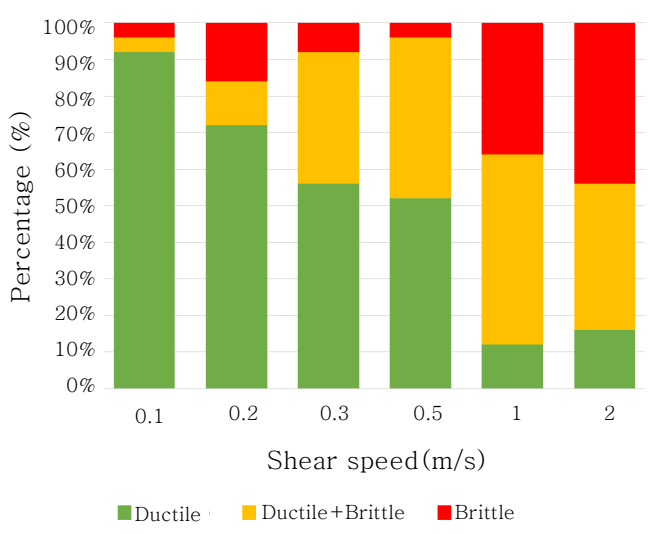

(b)

Fig. 9 Percentage of brittle fracture modes in the SAC305/ ENEPIG solder joint with the MTO of Ni-P plating solution. (a) $0 \mathrm{MTO}$ and (b) $3 \mathrm{MTO}$

void의 크기와 수가 증가되었다) ${ }^{4)}$ 이러한 접합 계면에 서의 nano-void의 증가는 취성파괴율을 증가시키고, 따 라서 전단강도 값이 낮아지게 된다. 본 연구의 $\mathrm{ENEPIG}$ 표면처리의 경우에도 무전해 $\mathrm{Ni}$ 층이 용융 솔더와 접촉 하여 반응하기 때문에 ENIG의 경우와 같이 nano-void 가 형성되고, 이러한 nano-void가 취성파괴에 영향을 주는 것으로 판단된다. 향후에 ENEPIG의 무전해 $\mathrm{Ni}$ 층과 SAC305솔더 접합부 계면에서 형성되는 nano-void 에 대한 관찰이 진행될 예정이다.

\section{4. 결 론}

본 연구에서는 ENEPIG 표면처리에서 무전해 $\mathrm{Ni}$ 도 금액의 $\mathrm{MTO}$ 를 변화했을 때, 솔더 접합부의 취성파괴 를 고속전단강도 시험을 통해 관찰하였다.

1) $\mathrm{ENEPIG}$ 의 무전해 $\mathrm{Ni}$ 도금액의 $\mathrm{MTO}$ 가 증가될 경우, 솔더 리플로우 후의 계면 IMC의 두께 차이가 크 지 않았으나, 500시간 시효 처리 후에는 $3 \mathrm{MTO}$ 샘플 이 $0 \mathrm{MTO}$ 샘플보다 높은 계면 IMC 두께를 보였다.

2) 무전해 $\mathrm{Ni}$ 도금액 $\mathrm{MTO}$ 가 $0 \mathrm{MTO}$ 에서 $3 \mathrm{MTO}$ 
로 증가되면 전단강도가 낮아지는데, 그 이유는 $3 \mathrm{MTO}$ 샘플의 $0 \mathrm{MTO}$ 샘플보다 취성파괴 모드가 증가했기 때 문이다.

$$
\text { 후기 }
$$

본 연구는 산업통상자원부의 연구사업으로 수행되었 습니다. 본 연구와 관련하여 도움을 주신 (주)엠케이켐 앤텍社에 감사의 말씀을 전합니다.

\section{References}

1. N. Biunno, A root cause failure mechanism for solder joint integrity of electroless nickel/immersion gold surface finishes, Proc. IPC Printed Circuits Expo1999, Paper (1999)

2. M. Amagai, Y. Toyoda, T. Ohnishi and S. Akita, High drop test reliability, lead-free solders, Proceedings of 54th Electronic Components and Technology Conference 2 (2004), 1304-1309 Vol.1302

3. H. Kim, M. Zhang, C. M. Kumar, D. Suh, P. Liu, D. Kim, M. Xie and Z. Wang, Improved Drop Reliability Performance with Lead Free Solders of Low Ag Content and Their Failure Modes, Proceedings 57th Electronic Components and Technology Conference (2007), 962967

4. W. Seo, K.-H. Kim, J.-H. Bang, M.-S. Kim and S. Yoo, Effect of Bath Life of $\mathrm{Ni}(\mathrm{P})$ on the Brittle-Fracture Behavior of Sn-3.0 Ag-0.5 Cu/ENIG, J. Electron. Mater. 43 (2014), 4457-4463

5. B.-S. Lee, Y.-H. Ko, J.-H. Bang, C.-W. Lee, S. Yoo, J.-K. Kim and J.-W. Yoon, Interfacial reactions and mechanical strength of $\mathrm{Sn}-3.0 \mathrm{Ag}-0.5 \mathrm{Cu} / \mathrm{Ni} / \mathrm{Cu}$ and $\mathrm{Au}-$ $20 \mathrm{Sn} / \mathrm{Ni} / \mathrm{Cu}$ solder joints for power electronics applications, Microelectron, Reliab. 71 (2017), 119-125

6. Y.-C. Sohn and J. Yu, Correlation between chemical reaction and brittle fracture found in electroless $\mathrm{Ni}(\mathrm{P}) /$ immersion gold-solder interconnection, J. Mater. Res. 20 (2005), 1931-1934

7. M. Ratzker, A. Pearl, M. Osterman, M. Pecht and G. Milad, Review of Capabilities of the ENEPIG Surface Finish, J. Electron. Mater. 43 (2014), 3885-3897
8. J. Y. Kim, J. Yu and S. H. Kim, Effects of sulfide-forming element additions on the Kirkendall void formation and drop impact reliability of $\mathrm{Cu} / \mathrm{Sn}-3.5 \mathrm{Ag}$ solder joints, Acta Mater. 57 (2009), 5001-5012

9. L. Yin, F. Wafula, N. Dimitrov and P. Borgesen, Toward a better understanding of the effect of $\mathrm{Cu}$ electroplating process parameters on Cu3Sn voiding, J. Electron. Mater. 41 (2012), 302-312

10. C. Yu, Y. Yang, K. Wang, J. Xu, J. Chen and H. Lu, Relation between Kirkendall voids and intermetallic compound layers in the $\mathrm{SnAg} / \mathrm{Cu}$ solder joints, J. Mater. Sci. Mater. Electron. 23 (2012), 124-129

11. J. Yu and J. Kim, Effects of residual S on Kirkendall void formation at $\mathrm{Cu} / \mathrm{Sn}-3.5 \mathrm{Ag}$ solder joints, Acta Mater. 56 (2008), 5514-5523

12. J. Standard and S. S. T. Association, Solder Ball Shear, JESD22-B117A, Oct (2006)

13. D. Goyal, T. Lane, P. Kinzie, C. Panichas, K. M. Chong and O. Villalobos, Failure mechanism of brittle solder joint fracture in the presence of electroless nickel immersion gold (ENIG) interface, Electronic Components and Technology Conference, 2002. Proceedings. 52nd (2002), 732-739

14. K. Harada, S. Baba, Q. Wu, H. Matsushima, T. Matsunaga, Y. Ucgai and M. Kimura, Analysis of solder joint fracture under mechanical bending test, Electronic Components and Technology Conference, 2003. Proceedings. 53rd (2003), 1731-1737

15. F. Song, S. R. Lee, K. Newman, B. Sykes and S. Clark, High-speed solder ball shear and pull tests vs. board level mechanical drop tests, correlation of failure mode and loading speed, Electronic Components and Technology Conference, 2007. ECTC'07. Proceedings. 57th (2007), 1504-1513

16. C. E. Ho, R. Y. Tsai, Y. L. Lin and C. R. Kao, Effect of $\mathrm{Cu}$ concentration on the reactions between $\mathrm{Sn}-\mathrm{Ag}-\mathrm{Cu}$ solders and Ni, J. Electron. Mater. 31 (2002), 584-590

17. C.-F. Tseng, T.-K. Lee, G. Ramakrishna, K.-C. Liu and J.-G. Duh, Suppressing Ni3Sn4 formation in the $\mathrm{Sn}-\mathrm{Ag}-\mathrm{Cu}$ solder joints with $\mathrm{Ni}-\mathrm{P} / \mathrm{Pd} / \mathrm{Au}$ surface finish, Mater. Lett. 65 (2011), 3216-3218

18. K. Newman, BGA brittle fracture-alternative solder joint integrity test methods, Electronic Components and Technology Conference, 2005. Proceedings. 55th (2005), 1194-1201 